\title{
Effects of Multicomponent Exercise with Aromatherapy Massage Program for Older Adult on Performance and Satisfaction
}

\author{
Lee-Lan Cheng* \\ Ph. D. Student, Department of Adult and Continuing Education, National Chung-Cheng University, Chiayi, \\ Taiwan
}

*Corresponding Author: Lee-Lan Cheng, Ph. D. Student, Department of Adult and Continuing Education, National Chung-Cheng University, Chiayi, Taiwan

\begin{abstract}
:
Purpose: The purpose of this study was to examine the effects of multicomponent exercise with aromatherapy massage program for older adult on performance and satisfaction. Methods: This study applied a preexperimental design and conducted a one-group pretest-posttest experimental design. Participants were 52 volunteer older adults (above 65 years old) enrolled in functional physical fitness program at senior center. The study was implemented during a ten-week period.

The pretest was administered during the first week. The study consisted of five functional fitness instructional units plus an aromatherapy massage instruction. Participants completed a multicomponent physical fitness program, the effects of learning outcome and motivational strategies were examined across posttest and satisfaction. Results: The results revealed that the model of multidimensional exercise program on functional physical fitness is significant effects on older adults. The results of this study lend support to others who indicate that exercise prescription positively affects older adults' cognitive and functional fitness. In addition, the most important finding to emerge from this study was that participants who worked multicomponent exercise with aromatherapy massage program reported greater overall satisfaction.
\end{abstract}

Conclusion: The multicomponent exercise with aromatherapy massage program may promote the effects on performance and satisfaction for older adults. The implications for multicomponent exercise with aromatherapy massage program and motivation strategies to promote older adults for functional fitness instruction and future research are discussed.

Keywords: Multicomponent exercise, Satisfaction, Older Adults, Aromatherapy Massage

\section{INTRODUCTION}

According to active aging proposed by the World Health Organization, participation (the creation of social participation channels), health (the establishment of an environment for physical and mental health), and security (social and economic security and life safety), as well as the comprehensive health promotion concept based on exercise prescription on fitness perspective that was developed by the American College of Sports Medicine (ACSM, 2016; Gonçalves, et al, 2019; Huang, \& Wang, 2018; Jones \& Rose, 2005). These types of well-being complement each other and affect lifestyle and health quality in older adults.

A meta-analysis reported that physical activity or exercise is associated with improvements in attention, processing speed, and executive function in older adults with or without cognitive impairments (Smith, 2012). In addition, many studies have examined the benefits of exercise in older adults living in skilled nursing facilities, where it is convenient to conduct and assess the effect of group-centered interventions (ACSM, 2016; Wojtek, \& Chodzko-Zajko, 2015; Suzuki, \& Bocalini, 2018). These institutionalized populations, who often have varying degrees of cognitive impairment, can be challenging both when trying to establish motivation for exercise and when creating opportunities for group reinforcement and participation (Chang, 2015; Huang, Wang, \& Lin, 2016). Study variables on which exercise interventions have had an impact include those directly related to the exercise itself changes in mobility or strength.

However, because the results of these studies differed largely due to differences in methodology, 
exercise prescription, learner characteristics, the sufficient evidence has not been garnered regarding the relationship between exercise program and effective conditions for older adults. Some researchers report that multicomponent exercise program positively affected performance in the instructional lessons (Suzuki, et al., 2012; Rikli, \& Jones, 2001). Some research had not found a significant effect for performance and attitudes when instructors used a general exercise training and instructional strategies (Huang, and Wang, 2018; Jones, \& Rose, 2005). These differences in findings could be due to the types of learners who participated in domain of study. In addition, Research have reported that instructional design and learner characteristics impact performance and motivation in a functional fitness studies. Factors such as instructional method, program design, personality, gender and ability have impacted outcomes in some of the studies (ACSM, 2016; Ferreira, \& Marmeleira, 2017; Wang, \& Lin, 2016). Researchers suggest that individuals' motivational characteristics may influence how they perform in training program environments (Huang \& Wang, 2018; Wojtek, \& Chodzko-Zajko, 2015).

As indicated by past studies, multiple complex factors influence exercise participation behavior in older adults; behavior of older adults can be changed through the use of appropriate learning systems, teaching methods, and prescribing exercise strategies (Jones, \& Rose, 2005; Rikli, \& Jones, 2001; Suzuki, et al, 2012). Aromatherapy massage may be a feature of multicomponent instruction to promote a more effective training environment and participating motivation for older adults. Aromatherapy massage is a nonpharmacologic method used for symptom control. Its main aim is not to cure the disease but to control the symptoms emerging as a result of the disease (Başaran, 2009, Buckle, 2001, Kim, Nam, \& Paik, 2005; Lindquist et al., 2014).

According to studies, the use of aromatherapy massage in nursing practice is important to improve overall health and accelerate recovery. Aromatherapy massage is preferred in many areas because of its efficacy in relieving pain, strengthening the immune system, alleviating inflammation, and increasing sleep quality and quality of life of the patients (Fontaine, 2005, Gok Metin \& Ozdemir, 2016). In addition, aromatherapy massage can also be performed for pain, stiffness, decreased physical function, sleep disturbances, anxiety, and depression experienced by patients with knee OA decrease the quality of life (Therkleson, 2010; Yip \& Tam, 2008).

Traditional instructional design to exercise programming for older adults have generally focused on improving functional physical fitness. Although these goals may be appropriate for some benefits for older adults, alternative goals may be helpful to accommodate the needs of older adults, there are few research-based guidelines delving into prescribing exercise which combined with aromatherapy massage to enhance depth of effective processing on learning outcome. This study aimed to investigate effects of aromatherapy massage on multicomponent physical fitness for older adult on performance and satisfaction.

More specifically, the following questions were addressed in this study: (1) Are there significant differences in the posttest during a multicomponent physical fitness program? (2) Do older adults in multicomponent physical fitness program possess better satisfaction?

\section{METHOD}

\subsection{Participants}

Participants were 60 volunteer older adults (above 65 years old) enrolled in functional physical fitness program at senior center. While participants in this class are required to participate in one study during an instructional program, participation in this particular study was not mandatory. Participants had the option not to participate or withdraw from the study at any time. Older adults with intellectual inadequacies, physical disabilities, and mental disabilities; adults who were not allowed to exercise according to the instructions of a doctor; and older adults with hypertension, past major heart surgery, abnormal chest pain, or sudden dizziness were excluded from the sample. Prior to the experiment, its objectives, content, measurement items, and matters requiring attention were explained to the participants, who signed consent forms confirming their voluntary participation in this study. The final analysis was performed on a sample of 52 volunteer participants. ( age: $68.76 \pm 6.06$, height: 162.9 \pm 8.2 , weight: $55.4 \pm 5.24$ ) . 


\subsection{Materials}

Materials used in this study were a multicomponent instructional fitness program, an instrument to measure student satisfaction of motivation, and a functional physical fitness performance posttest.

\subsubsection{The Multicomponent Exercise Program.}

The multicomponent exercise program principles and training methods (ACSM, 2016; Gonçalves, et al, 2019; Rose and Jones, 2005) used in the study was designed to help the older adults build their basic performance in functional physical fitness. During the practicing stage, older adults received immediate feedback in specific skill areas by instructor. This unit is designed for self-instruction and group learning. The content presented in the program consists of five segments: 1) Principles warmup and cool-down. 2) Flexibility training. 3) Resistance training. 4) Aerobic endurance training 5) Balance and mobility training (Rose and Jones, 2005). For experimental factor, the multicomponent program plus an aromatherapy massage instruction was applied for participants in the study. In pilot studies, the instructional lesson was reviewed and revised by two content experts of functional fitness instructor and three aromatherapy massage instructors. The instructional lesson was formatively evaluated using older adults of the target group, and was revised into its final form for instructional unite.

\subsubsection{Motivation Scale on Satisfaction}

Motivation was measured using this scale including simple, safety, self-efficacy and Satisfaction (Huang, Wang \& Lin, 2016). This scale consists of six questions that measure student perceptions toward the motivational characteristics of instruction in the affective area of satisfaction. A five-point Likert scale is used to answer the questions. The Cronbach alpha internal-consistency relationship reliability estimate of this scale is .86 .

\subsubsection{Posttest.}

After completing the instruction and practicing, all participants received a functional fitness of posttest. This posttest unit was adapted according to the standard senior functional fitness test (Rikli, \& Jones, 2001). The posttest was based on multicomponent of physical exercises intervention program on senior functional fitness. Data from the pilot studies were used to determine reliability estimates for posttest. Cronbach's alpha method was used to calculate the reliability of the posttest, and was found to have a value of .86 .

\subsection{Intervention}

The study was implemented during a ten-week period. The pretest was administered during the first week. The study consisted of five functional fitness instructional units plus an aromatherapy massage instruction. In addition, each group was given 20-minutes periods on each functional fitness practicing during the two to ninth week.

The study was conducted the functional physical fitness program for instruction and practicing in the senior center. Upon completion the ninth week of the lesson, each participant individually completed the motivational scale on satisfaction questionnaire. The posttest was delivered in the final week of the study.

The course design focused on the training for functional fitness and cognitive functions using various intervention tools including an active bar, functional physical and mental fitness platform, sweet circle and resistance ball, and aimed to improve functional fitness and cognitive performance for older adults (Huang, Wang, \& Lin, 2016). The duration of the intervention process was 90 minutes, which included 15 minutes of dynamic aerobic warm-up exercises, 30 minutes of resistance training, 30 minutes of cognitive function training, and 15 minutes of aromatherapy massage with stretching. Table 1 provides information regarding multi-exercise course prescription and implementation.

Table1. Multicomponent prescription and implementation

\begin{tabular}{|l|l|l|l|l|}
\hline $\begin{array}{l}\text { Teaching } \\
\text { process }\end{array}$ & $\begin{array}{l}\text { Dynamic aerobic } \\
\text { warm-up }\end{array}$ & $\begin{array}{l}\text { Resistance training } \\
\text { course }\end{array}$ & $\begin{array}{l}\text { Cognitive function } \\
\text { course }\end{array}$ & $\begin{array}{l}\text { Aromatherapy massage } \\
\text { with stretching }\end{array}$ \\
\hline Duration & 15 minutes & $\mathbf{3 0}$ minutes & 30 minutes & 15 minutes \\
\hline
\end{tabular}


Effects of Multicomponent Exercise with Aromatherapy Massage Program for Older Adult on Performance and Satisfaction

\begin{tabular}{|c|c|c|c|c|}
\hline Objective & $\begin{array}{l}\text { Increase body } \\
\text { temperature, } \\
\text { warm up joints, } \\
\text { prevent exercise } \\
\text { injuries. }\end{array}$ & $\begin{array}{l}\text { Strengthen pelvic core } \\
\text { muscles and upper and } \\
\text { lower limb muscles. }\end{array}$ & $\begin{array}{l}\text { Establish behavior } \\
\text { functions, improve } \\
\text { memory ability, } \\
\text { working memory, and } \\
\text { the ability to plan. }\end{array}$ & $\begin{array}{l}\text { Relax the body, prevent } \\
\text { accumulation of lactic } \\
\text { acid, increase flexibility } \\
\text { through massage and } \\
\text { stretching exercises, } \\
\text { accelerate excretion of } \\
\text { metabolic wastes. }\end{array}$ \\
\hline Content & $\begin{array}{l}\text { Main focus on } \\
\text { low-intensity } \\
\text { aerobic exercises, } \\
\text { full-body } \\
\text { coordination, } \\
\text { change of } \\
\text { direction, and } \\
\text { training in turns. }\end{array}$ & $\begin{array}{l}\text { Training of abdominal } \\
\text { muscles, } \\
\text { muscles, hip muscles, } \\
\text { lower limb muscles, } \\
\text { etc. }\end{array}$ & $\begin{array}{l}\text { 1. Increase cognitive } \\
\text { and executive control } \\
\text { abilities in learning } \\
\text { movements. } \\
\text { 2. With regard to } \\
\text { physical performance, } \\
\text { improve full-body } \\
\text { physical activity. } \\
\text { 3. Properly complete } \\
\text { all tasks in an } \\
\text { arranged sequence } \\
\text { during exercises. }\end{array}$ & $\begin{array}{l}\text { Massage Relaxation } \\
\text { and stretching help to } \\
\text { recover from tiring } \\
\text { exercises and stretch } \\
\text { upper and lower limbs. }\end{array}$ \\
\hline $\begin{array}{l}\text { Matters } \\
\text { needing } \\
\text { attention }\end{array}$ & $\begin{array}{l}\text { Maintain body } \\
\text { balance, follow } \\
\text { own rhythm and } \\
\text { the instructor. }\end{array}$ & $\begin{array}{l}\text { Avoid } \\
\text { breathing } \\
\text { exercises, during } \\
\text { movements that are } \\
\text { too difficult or require } \\
\text { more stretching, avoid } \\
\text { excessively intense } \\
\text { exercises and joint } \\
\text { angles. }\end{array}$ & $\begin{array}{l}\text { Pay attention to older } \\
\text { adults' physical state, } \\
\text { avoid exercises in } \\
\text { case of poor mental } \\
\text { health, make } \\
\text { adjustments } \\
\begin{array}{l}\text { depending on the } \\
\text { situation. }\end{array}\end{array}$ & 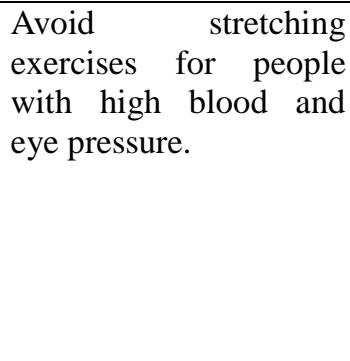 \\
\hline
\end{tabular}

\subsection{Design and Data Analysis}

This study applied a pre-experimental design and conducted a one-group pretest-posttest experimental design. The dependent variables were functional fitness on performance and a measure of participant's motivation on satisfaction. The exercise course was conducted by a trained instructor. The participants completed a pre-test that covered their basic personal data, health status, and functional fitness status one week before the exercise course intervention.

The following statistical analyses were conducted using SPSS for Windows 22.0 for the data collected in this study: Basic data was analyzed using descriptive statistics to explore the distribution of basic variables among the participants. The t-test was used to analyze performance for functional fitness scores before and after the course intervention; $\alpha=.05$ indicated statistical significance.

\section{RESULTS}

\subsection{Data of Participants}

Participants were 60 volunteer older adults (above 65 years old) enrolled in functional physical fitness program at senior center. While participants in this class are required to participate in one study during an instructional program, participation in this particular study was not mandatory. Participants had the option not to participate or withdraw from the study at any time. Prior to the experiment, its objectives, content, measurement items, and matters requiring attention were explained to the participants, who signed consent forms confirming their voluntary participation in this study. The final analysis was performed on a sample of 52 volunteer subjects: male: $26.9 \%$, female: $73.1 \%$, age: 68.76 \pm 6.06 , height: $162.9 \pm 8.2$, weight: 55.4 \pm 5.24 .

Table3.1. Participants' basic data

\begin{tabular}{|c|c|c|c|c|}
\hline Gender & \multicolumn{2}{|c|}{ Number } & \multicolumn{2}{c|}{ Percentage } \\
\hline Male & \multicolumn{2}{|c|}{14} & \multicolumn{2}{c|}{$73.1 \%$} \\
\hline Female & \multicolumn{2}{|c|}{38} & Max. & Min. \\
\hline Variable & Mean & SD & 62 & 92 \\
\hline Age $($ years $)$ & 69.76 & 7.06 & 47 & 140 \\
\hline Height $(\mathrm{cm})$ & 162.9 & 9.2 & 45 & 67.2 \\
\hline Weight $(\mathrm{kg})$ & 55.4 & 7.24 & \\
\hline
\end{tabular}


Effects of Multicomponent Exercise with Aromatherapy Massage Program for Older Adult on Performance and Satisfaction

\subsection{Performance on Functional fitness}

The statistical results on Table 3.2 indicated a significant progress $\Delta(\%)$ in the participants' functional fitness scores. The result revealed that the functional physical fitness on shoulder flexibility $\Delta(29.15 \%)$, and cardio respiratory endurance $\Delta(282.63 \%)$, muscles strengths $\Delta(6.46 \%)$, and dynamic mobility $\Delta(-9.68 \%)$ reached a significantly different. In addition, the result revealed that this training ways of multidimensional fitness plus an aromatherapy massage program on functional physical fitness increased on shoulder flexibility and cardio respiratory endurance, muscles strengths, and dynamic mobility. The results revealed that the model of multidimensional exercise program on functional physical fitness is significant effects on older adults.

Table3.2. Index of progress on the functional fitness

\begin{tabular}{|l|l|l|l|l|}
\hline Fitness & pretest & Posttest & $\Delta(\%)$ & $t$ \\
\hline shoulder flexibility & $-13.64 \pm 10.38$ & $-9.66 \pm 9.03$ & 29.15 & $-5.39 * * *$ \\
\hline $\begin{array}{l}\text { cardiorespiratory } \\
\text { endurance }\end{array}$ & $107.26 \pm 7.29$ & $155.45 \pm 6.63$ & 282.63 & $-5.17 * *$ \\
\hline muscles strength & $16.70 \pm 2.87$ & $17.73 \pm 2.66$ & 6.46 & $-2.26 * *$ \\
\hline dynamic mobility & $9.21 \pm 1.91$ & $8.30 \pm 1.20$ & -9.68 & $3.69 * * *$ \\
\hline
\end{tabular}

Note : Aindex of various $(\%)=[($ posttest-pretest $) /$ pretest $] \times 100 \%$

Table3.3. Performance on functional fitness

\begin{tabular}{|c|c|c|c|c|c|}
\hline Fitness & Time & $\mathrm{M}$ & SD & $t$ & $p$ \\
\hline \multirow{2}{*}{$\begin{array}{l}\text { shoulder } \\
\text { flexibility }\end{array}$} & Before & -13.54 & 10.28 & \multirow{2}{*}{ - $\quad 5.39 * * *$} & \multirow[t]{2}{*}{.00} \\
\hline & After & -9.36 & 9.23 & & \\
\hline \multirow{2}{*}{$\begin{array}{l}\text { cardiorespiratory } \\
\text { endurance }\end{array}$} & Before & 104.26 & 7.69 & \multirow{2}{*}{$-5.17 * * *$} & \multirow[t]{2}{*}{.00} \\
\hline & After & 146.45 & 6.73 & & \\
\hline \multirow[t]{2}{*}{ muscles strength } & Before & 14.70 & 2.57 & \multirow{2}{*}{$-2.26 * * *$} & \multirow[t]{2}{*}{.00} \\
\hline & After & 17.43 & 2.96 & & \\
\hline \multirow{2}{*}{$\begin{array}{l}\text { Dynamic } \\
\text { mobility }\end{array}$} & Before & 10.61 & 1.81 & \multirow[t]{2}{*}{$3.69 * * *$} & \multirow[t]{2}{*}{.00} \\
\hline & After & 9.63 & 1.41 & & \\
\hline
\end{tabular}

$\mathrm{N}=52, * * * p<.001$

\subsection{Motivation on Satisfaction}

Satisfaction was measured using the Instructional Materials Motivation Scale (Huang, Wang, Lin, 2016). Mean scores and standard deviations for satisfaction can be found in Table3.4. Results indicated that type of instructional method had a significant effect on satisfaction. Subjects who worked in multicomponent program plus an aromatherapy massage instruction reported greater satisfaction with the instruction $(\mathrm{M}=3.54, \mathrm{SD}=1.02)$

Table3.4. Performance on Means and Standard Deviations for Satisfaction items

\begin{tabular}{|l|l|l|}
\hline \multirow{2}{*}{ SCALE ITEM } & \multicolumn{2}{|c|}{ Total } \\
\cline { 2 - 3 } & $\mathrm{M}$ & SD \\
\hline 1. Participation was satisfying & & 3.860 .93 \\
\hline 2. Body and muscle were relax & 3.681 .06 & \\
\hline 3. Would like to participate in activity & 3.841 .84 & 2.501 .48 \\
\hline 4. Did not enjoy activity & & \\
\hline 5. Felt comfortable to complete activity & 3.381 .22 & 3.381 .22 \\
\hline 6. Activity was well designed & & \\
\hline Total & 3.541 .02 & \\
\hline
\end{tabular}

*Note: A five-point Likert scale was evaluation for each item on satisfaction

\section{DISCUSSION}

The purpose of this study was to examine the effects of multicomponent exercise with aromatherapy massage program for older adult on performance and satisfaction. This study was conducted the functional physical fitness program for instruction and practicing in the senior center. Upon completion the ninth week of the lesson, each participant individually completed the motivational 
scale on satisfaction questionnaire. The posttest was delivered in the final week of the study. The results revealed that the model of multidimensional exercise program on functional physical fitness is significant effects on older adults. The results of this study lend support to others who indicate that exercise prescription positively affects older adults' cognitive and functional fitness (Erickson, et al.,2012; Suzuki, et al., 2017; Gonçalves, et al, 2019). A retrospective review study revealed that aerobic exercises combined with double-task training or stretching exercises improved cognitive and physical functions in adults with MCI or early Alzheimer's disease (Chu, 2012; Gonçalves, et al, 2019).

The most important finding to emerge from this study was that the effects of multicomponent exercise with aromatherapy massage program for older adult on performance and satisfaction. The results of this study lend support to others who indicate that multicomponent exercise program positively affects student achievement, productivity and attitude (Huang \&Wang, 2018; Suzuki, et al., 2017; Gonçalves, et al, 2019). One possible explanation for this finding is that instruction with multicomponent exercise with aromatherapy massage design are more likely to be motivated and learn. Since students with a satisfaction motive prefer to participate in activities that allow them enjoy toward the program (Huang \& Wang, 2018; Gok Metin \& Ozdemir, 2016).

\section{CONCLUSION AND SUgGeSTION}

This study has some implications for those who design program for older adults. Instructional functional fitness program can successfully increase older adult performance and motivation by employing instruction with multicomponent factors on design that were originally designed for traditional design on physical activities for older adults. The current study suggests that multicomponent exercise and motivational strategies can be used with instructional activities lessons for older adults. The study also indicates that designers should consider multicomponent design, motivational factors, for example, simple, safety, self-efficacy and satisfaction when assigning older adults to instruction that requires them to accomplish goals.

Future studies should also examine other older adults' health conditions including sarcopenia, frailty, cognitive impairment, such as Alzheimer disease, and poor nutritional status that might influence outcomes in multicomponent exercise learning settings. The relatively short duration of the treatment and the effect of instructional control group design may have influenced the outcomes. Extending the experimental time for overall instruction could produce different results for satisfaction and performance. Further research should identify critical evaluation elements including difference age group, cognitive function or frailty under which effective instructional design can be generated and maintained on the domain of functional fitness training setting for older adults.

\section{REFERENCES}

[1] American College of Sports Medicine. (2016). ACSM'S exercise for older adults. Philadelphia, USA.

[2] Barbar, A. (2015). Essential oils used in aromatherapy: A systemic review:

[3] Asian Pacific Journal of Tropical Biomedicine, 5 (8), pp. 601-611.

[4] Başaran, A. (2009). Doğal aromaterapötik bitkiler ve uçucu yağlar Türkiye Klinikleri. Journal of Medical Sciences, 29 (5 Suppl 1), pp. 86-94.

[5] Buckle, J. (2001). The role of aromatherapy in nursing care. Holistic Nursing Care, 36 (1), pp. 57-72.

[6] Chang, L. Y. (2015). The effects of functional fitness for older people during core strength training program. Master Thesis, National Chung Cheng University.

[7] Chu, Y. H. (2013). The effects of physical activity in cognitive function. The Journal of Long-term Care, $17(1), 11-21$.

[8] Erickson, K. I., Weinstein, A. M., \& Lopez, O. L. (2012) . Physical activity, brain plasticity, and Alzheimer's disease. Archives of medical research, 43(8), 615-621.

[9] Ferreira, S., \& Marmeleira, J. (2017). Physical activity and functional fitness in older adults with cognitive impairment. In Motricidade; Book of Abstracts of the International Congress of Exercise and Health, Sports and Human Development, CIDESD (Vol. 13, No. 1, pp. 174-175).

[10] Fontaine, L. (2005). Complementary and alternative therapies for nursing practice aromatherapy (2nd ed.), Pearson Prentice Hall, Upper Saddle River, NJ: pp. 143-156.

[11] Gok Metin, Z., \& Ozdemir, L. (2016). The effects of aromatherapy massage and reflexology on pain and fatigue in patients with rheumatoid arthritis: A randomized controlled trial Pain, Management Nursing, 17 (2), pp. 140-149. 
[12] Gonçalves, I. O., Bandeira, A. N., Coelhojunior, H. J., Aguiar, S. S., Camargo, S. M. Asano, R. M. \& Junior, M. L. (2019). Multicomponent Exercise on Physical Function, Cognition and Hemodynamic Parameters of Community-Dwelling Older Adults: A Quasi-Experimental Study. Published online 2019 Jun 20. doi: 10.3390/ijerph16122184.

[13] Huang, C. Y., Wei, H. C. \& Cheng, H. C. (2010). Relationship between regular exercise in older adults and successful aging: Model construction and indicator development and application. NSC Project Report.

[14] Huang, C. Y., Wang, H. H. \& Lin, M. J. (2016). The effects of functional physical and mental fitness platform for active ageing. Annual global report on Innovation in Active, Healthy and Smart Ageing Sector. Beijing Science \& Technology Publishing Press.

[15] Jones, C. J., Rose, D. J. (2005). Physical Activity Instruction of Older Adults. Champaign, IL: Human Kinetics.

[16] Kim, M. J. Nam, E. S. Paik, S. I. (2005), The effect of aromatherapy on pain, depression and life satisfaction of arthritis patients. Taehan Kanho Hakhoe Chi, 35 (1): pp. 186-194.

[17] Lindquist, R., Snyder, M. \& Tracy, M. F. (2014). Complementary \& Alternative Therapies in Nursing (7th ed.), Springer, New York : pp. 323-343.

[18] Rikli, R. E., \& Jones, C. J. (2001). Senior fitness test manual. Champaign, IL: Human Kinetic.

[19] Smith, P. J, Blumenthal, J. A, Hoffman, B. M, Cooper H, Strauman, T. A, Welsh-Bohmer K, Browndyke, J. N, \& Sherwood, A. (2010). Aerobic exercise and neurocognitive performance: a meta-analytic review of randomized controlled trials. Psychosom Med. 72(3):239-252. doi: 10.1097/PSY.0b013e3181d14633.

[20] Suzuki, F. S. \& Bocalini, D. S. (2018). Effets of a Multicomppnent Exercise Program on the Functional Fitness in Elderly Women. CICLINICAL EXERCISE MEDICINE • Rev Bras Med Esporte 24 (01) https://doi.org/10.1590/1517-869220182401179669

[21] Suzuki, T., , Shimada, H., Makizako, H., Doi, T., Yoshida, D., Tsutsumimoto, K., Anan, Y., Uemura, K., Lee, S., and Park, H. (2017). Community-Based Intervention for Prevention of Dementia in Japan, The Journal of Prevention of Alzheimer's Disease - JPAD. Volume 2, Number ,1-6.

[22] Therkleson, T. (2010). Ginger compress therapy for adults with osteoarthritis. Journal Advanced Nursing, 66 (10), pp. 2225-2233.

[23] Wojtek, J., \& Chodzko-Zajko, (2015). ACSM's Exercise for older adults. Wolters Kluwer Health, Philadelphia.

[24] Yip, Y. B. \& Tam, A. C. Y. (2008). An experimental study on the effectiveness of massage with aromatic ginger and orange essential oil for moderate-to-severe knee pain among the elderly: in Hong Kong Complementary Therapies in Medicine, 16 (3), pp. 131-138.

\section{AUTHOR'S BIOGRAPHY}

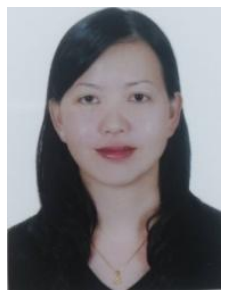

Lee-Lan Cheng, is a candidate student of $\mathrm{Ph}$. D program in Department of Adult and Continuing Education, National Chung-Cheng University, Chiayi, Taiwan, Taiwan, R. O. C. Currently, teaches physical education and functional fitness for older adults in society and is also an external evaluator for the fitness and consultant at a fitness promotion for society senior citizens. Cheng's field of expertise lies in sports and health promotion, sports pedagogy, Physical activity instruction of older adults, and the design of educational sports programs for active-aging learners.

Citation: Lee-Lan Cheng. "Effects of Multicomponent Exercise with Aromatherapy Massage Program for Older Adult on Performance and Satisfaction" International Journal of Humanities Social Sciences and Education (IJHSSE), vol 8, no. 8, 2021, pp. 120-126. doi: https://doi.org/10.20431/2349- 0381.0808011.

Copyright: (C) 2021 Authors. This is an open-access article distributed under the terms of the Creative Commons Attribution License, which permits unrestricted use, distribution, and reproduction in any medium, provided the original author and source are credited. 